\title{
Estimación de los costes de construcción de viviendas rústicas mediante Redes Neuronales Artificiales
}

\section{Estimation of rustic housing construction costs through Artificial Neural Networks}

\author{
J. F. Coloma $^{(*)}$, L. R. Valverde ${ }^{(*)}$, M. García ${ }^{(*)}$
}

\section{RESUMEN}

La Administración Pública y el promotor privado buscan tener un conocimiento previo de los costes de cualquier edificación. Existen en la literatura numerosas metodologías que permiten realizar la valoración de un inmueble, pero siempre se ha realizado para viviendas urbanas en ciudades grandes o medianas. Esta investigación propone el uso de Inteligencia Artificial para el estudio de viviendas rústicas en pequeñas ciudades como la de Cáceres (España). La investigación propone un procedimiento de Redes Neuronales Artificiales (RNA) para conseguir por un lado estimar a través de un método automático el coste de construcción de la vivienda rústica y por otro, identificar los atributos más determinantes en su precio final. La RNA diseñada establece como variables más influyentes en el precio final del inmueble los espacios húmedos (baños y cocina), la superficie construida y la antigüedad por este orden, diferenciándose de las variables más determinantes en el precio de las viviendas urbanas en grandes o medianas ciudades que son la superficie construida y su ubicación.

Palabras clave: Redes neuronales artificiales, valoración inmobiliaria, costes de vivienda.

\section{ABSTRACT}

The Public Administration and the private developer seek to have a prior knowledge of the costs of any building. There are numerous methodologies in the literature that allow the real estate valuation of a property, but it has always been done for urban houses in large or medium-sized cities. This research proposes the use of Artificial Intelligence for the study of rustic houses in small cities such as Caceres (Spain). The research proposes a procedure of Artificial Neural Networks (ANN) to achieve on the one hand, to estimate, through an automatic method, the construction cost of rustic houses and, on the other hand, to identify the most determining attributes in its final price and its marginal weight. The designed ANN establishes as more influential variables in the final price of the property the wet spaces (bathrooms and kitchen), the constructed surface and the age in this order, differentiating themselves from the most determining variables in the price of urban houses in large or medium-sized cities that are the constructed surface and its location.

Keywords: Artificial neural networks, real estate valuation, housing costs.

(*) Universidad de Extremadura (España).

Persona de contacto/Corresponding author: jfcoloma@unex.es (J. F. Coloma)

ORCID: http://orcid.org/oooo-0002-9983-6881 (J. F. Coloma); http://orcid.org/oooo-0oo1-5205-0198

(L. R. Valverde), http://orcid.org/oooo-0001-6250-5600 (M. Garcia)

Cómo citar este artículo/Citation: Coloma, J. F.; Valverde, L. R.; García, M. (2019). Estimación de los costes de construcción de viviendas rústicas mediante Redes Neuronales Artificiales. Informes de la Construcción, 71(554): e293. https://doi.org/10.3989/ic.62206

Copyright: (C) 2019 CSIC. Este es un artículo de acceso abierto distribuido bajo los términos de la licencia de uso y distribución Creative Commons Reconocimiento 4.o Internacional (CC BY 4.0). 


\section{INTRODUCCIÓN}

La valoración inmobiliaria es de gran interés para todos los ciudadanos, ya que se encuentra presente en numerosas situaciones cotidianas, como la compra de un inmueble, la solicitud de un préstamo hipotecario o el pago del impuesto de bienes inmuebles (IBI). El conocimiento previo del coste de una edificación se hace necesario para poder determinar los riesgos de su inversión. Los más interesados serán las Administraciones Públicas (en calidad de promotoras o de colaboradoras mediante ayudas) y los promotores privados, incluyendo a los redactores de los proyectos de ejecución y a las empresas constructoras, que buscan tener un nivel de certeza alto en sus costes de producción.

En los antecedentes de arquitectura clásica aparecen ya referencias a los costes de construcción como por ejemplo Marco Vitruvio Pollion en sus textos de arquitectura (1). Sin embargo no es hasta los años 90 del siglo pasado, cuando aparecen las redes neuronales artificiales (RNA) como una rama de la inteligencia artificial y una alternativa viable para estimar los costes de construcción (2). En esa época en España todavía se seguían estudiando ábacos, indicadores y bancos de precios (3) hasta los estudios e investigaciones de Enrique Carvajal Salinas (4). En el inicio del siglo XXI es cuando los programas informáticos comercializados comienzan a ser útiles en la estimación de los precios de construcción (5).

A pesar de la existencia de todas estas investigaciones, los proyectistas, los promotores y los constructores en su desarrollo profesional, apenas cuentan con herramientas que les permitan tener un conocimiento económico del edificio paralelo al conocimiento científico y artístico del mismo.

A continuación se enumeran los problemas que presentan los métodos de predimensionado disponibles en software comercial (6):

- Requieren alto grado de definición del edificio, por tanto se pierde el concepto de estimador o predimensionador, pues se necesita el proyecto desarrollado casi al completo.

- Utilizan un elevado número variables muy técnicas, por lo que se necesitan unos elevados conocimientos de ingeniería, lo que dificulta su utilización por usuarios ajenos a la construcción (funcionarios de la Administración o personal de Banca).

- Se consideran pocas (o ninguna) variables del lugar, por lo que en realidad la estimación económica es ajena a los costes intrínsecos a la ubicación de la obra.

- No se establecen en los distintos modelos un nivel de certeza o confianza del resultado obtenido, por tanto se desconoce el grado de acierto del coste estimado y la incertidumbre económica sigue existiendo.

Para evitar estos problemas, surgen en el ámbito de la valoración inmobiliaria, los métodos de valoración automatizada caracterizados fundamentalmente por el empleo de técnicas matemáticas para la estimación del valor. Dentro de estos métodos los más usados han sido el de los precios hedónicos y las RNA (7). La gran mayoría de trabajos apoyan la utilización de las RNA por su robustez y gran capacidad para detectar relaciones no lineales entre variables. (8),(9).

Existen numerosas publicaciones de autores internacionales que utilizan las redes neuronales para estimar precios de vi- vienda y terrenos como Chiarazzo et al (10) que estudian en Italia la influencia de las condiciones ambientales en el precio de una vivienda fuera del ámbito urbano o Fachrurrazi et al (11) que modelan una red neural en Indonesia capaz de predecir los precios de las promociones públicas.

En España las primeras aportaciones a este campo se encuentran a primeros de este siglo. Caridad y Ceular (12) desarrollan para la ciudad de Córdoba una metodología hedónica para analizar el precio de un bien en función de sus características, a través de la estimación de los precios implícitos de sus componentes. Posteriormente se desarrollan trabajos similares pero utilizando redes neuronales como el de Mohamed (13) para la ciudad de Cádiz, Gallego (14) para Madrid, García Rubio (15) para Albacete, Lara (16) para Jaén y Landajo et al. (17) para la ciudad de Oviedo. Las investigaciones más recientes son las realizadas por Nuñez Tabales et al donde se busca para las ciudades de Córdoba y Sevilla (18),(19), la metodología de inteligencia artificial más adecuada en la valoración de una vivienda (preciso hedónicos contra RNA) y por otro lado, obtener los atributos más determinantes en la valoración de una vivienda.

Todos estos estudios realizan valoraciones de viviendas urbanas en ciudades grandes o medianas de España y dentro del perímetro urbano. En este tipo de vivienda la superficie construida y la ubicación son los factores que predominan sobre el resto. Alcázar- Molina y Ariza-López (20) proponen un modelo para realizar una valoración catastral de terrenos y su aprovechamiento, Azona (21) realiza un modelo Fuzzy para determinar un valor unitario de edificación con fines catastrales, pero faltaría investigar la valoración de los bienes inmuebles rústicos.

Esta investigación propone una herramienta basada en RNA que solvente las deficiencias identificadas anteriormente. Se pretende conseguir un doble objetivo. Por un lado, conocer a través de un método automático una previsión del coste de construcción y por otro, saber cuáles son los atributos determinantes del precio de una vivienda rural, estimando el peso marginal de cada atributo, de modo que se consiga valorar su importancia relativa sobre el precio total del inmueble. Es relevante, y más en tiempos de crisis económica, hallar el grado de incidencia de cada una de las variables estudiadas en el coste de construcción, para con ello poder tomar mejores decisiones de proyecto desde el punto de vista económico.

La RNA se va a calibrar y comprobar a partir de los datos de las viviendas de autopromoción construidas en la provincia de Cáceres (España). Este tipo de viviendas son el asentamiento humano con menos posibilidades especulativas y el más sostenible, abundante en Extremadura, de clara población rural y hace de la construcción un sistema más eficiente al conseguir optimizar el proceso económico de producción. Queda patente su oportunidad y la idoneidad de la investigación ya que es un estudio de optimización de recursos económicos en la producción ante la crisis en el sector de la construcción y un estudio de la autopromoción como una respuesta ante la falta de vivienda social de estos tiempos.

El resto del trabajo se estructura como sigue. La sección 2 explica la metodología seguida para generar el modelo de RNA, la sección 3 muestra los resultados experimentales obtenidos en la ciudad de Cáceres y la sección 4 describe las conclusiones obtenidas en esta investigación y su discusión. 


\section{METODOLOGÍA}

\subsection{Generación del modelo}

El primer paso para generar el modelo consiste en identificar el conjunto de variables de decisión que abstraen y resumen las características más relevantes de la estimación de los costes de construcción de las viviendas. La elección de estas variables es un proceso extremadamente crítico ya que, una elección errónea conduce automáticamente a resultados de baja calidad, independientemente del algoritmo que posteriormente se utilice.

Los criterios de elección que se han seguido en esta investigación son los siguientes:

a) Representar conceptos comparables con los de otros modelos actuales. En concreto, se eligen variables que actualmente se utilizan en el software comercial más utilizado en el mercado (Arquímedes y Presto).

b) Ser frecuentes en toda la literatura científica pasada y actual, para tener una cierta garantía de elección idónea y cultura de utilización, mesura y cuantificación de la misma.

c) Fácil obtención con la elaboración de un croquis y una visita al lugar, ya que de lo contrario se perdería el concepto de predimensionado o estimación previa.

d) No implicar una toma de decisiones técnicas de relevancia pues la utilización del modelo de estimación, debe ser realizada por usuarios sin formación técnica específica, como personal de la Administración Pública otorgante de la subvención o personal de Banca para el estudio de la financiación de la construcción.

Por las razones anteriormente expuestas, las variables estudiadas son las siguientes:

1. Año de construcción.

2. Población ( $\mathrm{n}^{0}$ de habitantes).

3. Ancho de vial (m).

4. Demolición de lo preexistente. Si o No.

5. Resistencia del terreno $\left(\mathrm{N} / \mathrm{mm}^{2}\right)$.

6. Topografía. Desnivel suficiente para construcción de una nueva planta. Si o No.

7. Superficie construida $\left(\mathrm{m}^{2}\right)$.

8. Superficie útil $\left(\mathrm{m}^{2}\right)$.

9. Fachada $\left(\mathrm{m}^{2}\right)$.

10. Medianeras $\left(\mathrm{m}^{2}\right)$.

11. Huecos exteriores $\left(\mathrm{m}^{2}\right)$.

12. Número de plantas.

13. Altura de coronación (m).

14. Anexos Garaje o Trastero. Si o No.

15. Locales húmedos $\left(\mathrm{m}^{2}\right)$.Cocinas, baños y aseos.

16. Zonas de no permanencia $\left(\mathrm{m}^{2}\right)$. Pasillos, vestíbulos y distribuidores.

De las 16 variables relacionadas, las 6 primeras están vinculadas al lugar, es decir, a la ubicación del edificio, y por tanto son inherentes a cada parcela. Las otras 10 variables estudiadas surgen como fruto de las decisiones del proyecto y se pueden variar y obtener nuevos resultados comparables entre sí.

\subsection{Caso de estudio y toma de datos}

La provincia de Cáceres se caracteriza por ser la segunda provincia en extensión de España (19.868 km²), cuenta con una baja densidad de población (20,65 hab $\left./ \mathrm{km}^{2}\right)$ y muy dispersa. $\mathrm{Su}$ economía se basa fundamentalmente en el sector agropecuario con escasa industria vinculada a la manufacturación de sus productos. Su Renta per cápita está por debajo del $75 \%$ media nacional y su estructura productiva se encuentra muy atomizada (22).

Como se ha comentado anteriormente, las viviendas objeto de estudio son las de autopromoción. Las condiciones exigidas y necesarias para adquirir una subvención de Vivienda de Autopromoción por la Junta de Extremadura son (23):

a) ser el propietario del suelo donde se construirá la vivienda.

b) permanecer 10 años como mínimo habitando el inmueble.

c) renta per cápita baja, según baremos establecidos en normativa específica.

La ayuda pública consiste en $21.000 €$ fijos a fondo perdido. Se permite la construcción de una vivienda de $90 \mathrm{~m}^{2}$ útiles con garaje y trastero. El diseño de la vivienda y su programa de usos no están sujetos a ningún condicionante específico que no sea las normativas vigentes en materia de vivienda en general de carácter autonómico.

La temporalidad queda delimitada por razones económicas en dos hitos: el año 2001, por la distorsión del mercado con el cambio de moneda de la peseta al euro y el año 2008, por la distorsión del mercado inmobiliario con el inicio de la crisis del sector.

Se parte de la Base de Datos de los expedientes de viviendas realizadas por la Junta de Extremadura sobre toda su Comunidad Autónoma. Hay 7.799 viviendas, de las cuales se han seleccionado los 596 expedientes en la provincia Cáceres desde el 2001 hasta el 2007, horquilla espacio-temporal de esta investigación (Figuras A y B del material adicional). De estos expedientes, se conoce la media de costes $(58.518,91 €)$ y la desviación típica de los mismos (16.979,71 €).

Una vez revisados los 596 expedientes de Cáceres (años 2001-2007), se han seleccionado 200 que estaban correctamente rellenos y no presentaban ningún defecto de forma ni contenido. Estas 200 propiedades serán utilizadas para la modelización de la RNA. Posteriormente a la generación del modelo, se analizarán los errores y la precisión realmente obtenida (24).

Las fuentes utilizadas para la obtención de los datos han sido las siguientes:

a) Los distintos casos se han obtenido mediante las bases de datos de la Consejería de Medio Ambiente y Rural, Políticas Agrarias y Territorio de la Junta de Extremadura. Esta información se ha contrastado con la base de datos del Colegio de Arquitectos de la demarcación de Cáceres (COADE).

b) Para las variables del lugar se ha girado visita a la obra y se ha consultado la cartografía topográfica y catastral existente.

c) Las variables de diseño se han obtenido de los Proyectos de Ejecución de los archivos Municipales y de Mancomunidades.

d) Los costes de construcción se han obtenido mediante entrevista a los promotores y constructores. 
Tras la tarea de campo de la obtención de los casos por toda la provincia de Cáceres, se elaboran las fichas correspondientes de los 200 casos estudiados. Todas las viviendas, cumplen las condiciones mínimas de habitabilidad, al contar en todos los casos con el correspondiente Certificado de Final de Obras, firmados por técnicos competentes y visado por los correspondientes colegios profesionales (25).

De todos y cada uno de los casos se elabora una ficha (Figura C del material adicional) con los datos del proyecto de ejecución obtenido de los distintos archivos municipales y tras realizar la visita girada al inmueble se elabora la tabla de la ficha de datos del lugar y el expediente administrativo.

En las fichas de cada uno de los casos se incorporó el dato de coste estimado mediante el programa Arquímedes de Cype Ingenieros (5), para poder tener ya una referencia del precio de construcción, con el cual poder comparar el modelo posteriormente.

\subsection{Red neuronal artificial basado en Perceptrón Multicapa}

En la valoración de inmuebles el Percetrón Multicapa -MultiLayerPreceptron (MLP) - es el método más usado (20), aunque también existen otros como la Función Base Radial -Radial Basis Function (RFB) (26).

Las RNA son modelos matemáticos computacionales que se pueden aplicar a sistemas informáticos en los cuales los microprocesadores, en lugar de disponerse "en serie" como en los ordenadores tradicionales, se conectan "en paralelo", formando capas con múltiples conexiones, tal y como se organiza la red de neuronas en el cerebro. Por supuesto que no se trata de simular un cerebro humano, sino sólo de construir un sistema que funcione de forma análoga y en pequeña escala. Inicialmente las "neuronas artificiales" eran microprocesadores, pero en la actualidad éstos han sido sustituidos en la mayoría de los casos por programas informáticos que imitan su funcionamiento.

Una red neuronal puede identificar relaciones mediante la presentación repetida de datos y también puede generalizar nuevos datos dentro del proceso. Las RNA cuentan con una estructura de conexión de información entrada-salida a través de tres capas básicas, concretamente la capa de entrada (input), donde los datos se insertan en el modelo, la capa oculta, donde se procesan los datos, y la capa de salida, donde se producen los resultados (27). Para el supuesto que se desarrolla en esta investigación se cuenta con una red de neuronas organizadas en 4 capas. En concreto, una capa de entrada con 16 neuronas (una por cada una de las variables descritas en la sección anterior), dos capas ocultas (ya que una red neuronal con dos capas ocultas es un clasificador universal) y una última capa, de salida, con una neurona que determinará el valor del coste de construcción.

El número de neuronas de la capa oculta se ajustó experimentalmente (prueba y error), resultando que los mejores valores para el entrenamiento se obtenían con 10 neuronas en cada una de las capas ocultas. La Figura 1 muestra gráficamente la arquitectura de la red neuronal con la que se trabajó inicialmente.

Cada neurona, al igual que ocurre en el cerebro, recibe datos de otras neuronas y posteriormente envía un dato a las neu-



Fig. 1. Esquema de la RNA Inicial.

ronas de la siguiente capa. La Figura 2 ilustra el proceso que sigue cada neurona para procesar la información entrante y producir una salida. En concreto, cada una de ellas calcula el sumatorio de entrada de los productos de cada variable por un peso (que se ajusta mediante el proceso de entrenamiento).

Posteriormente se calcula un valor de transferencia Y, aplicando la función sigmóide (Ecuación 1) que es la más utilizada para las RNA por su sencillez en la programación informática (28). (Véase la Figura D del material adicional).

$$
Y=\frac{1}{1+e^{-S}}
$$

Siendo S el sumatorio de los valores de entrada (inputs) multiplicados por sus pesos de ponderación e Y el coste estimado de la vivienda por la neurona (resultado).

La transformación logística o sigmoidal se realiza en la primera capa, para normalizar los valores de las variables de entrada. En la capa de salida se obtiene un valor Y, cuyo rango de variación estará en el intervalo $(0,1)$ y que debe transformarse en un valor de costes reales estimados $\mathrm{R}$.

Habiendo sometido las variables de entrada a una primera transformación normalizadora, la información de salida de las neuronas de esta primera capa oculta, se transmite a las neuronas de la segunda capa mediante expresiones similares y así sucesivamente hasta la capa de salida donde se obtiene

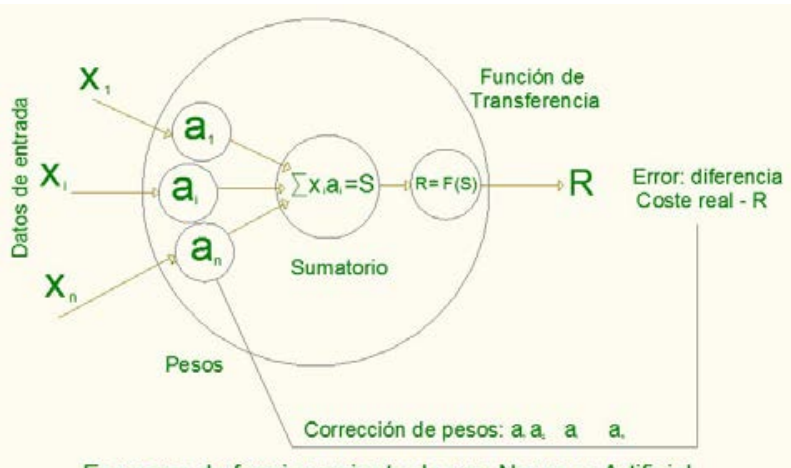

Esquema de funcionamiento de una Neurona Artificial

Fig. 2. Esquema funcional de una Neurona Artificial. 
Y que es transformada en la estimación de R. Z representa la información de salida de esa neurona (y no de toda la red). En la capa final, las diez neuronas de la segunda capa oculta transmiten la información a la variable $\mathrm{R}$ de valoración, mediante un esquema similar; pero no directamente las variables $\mathrm{x}_{\mathrm{i}}$ a la $\mathrm{R}$ mediante una neurona.

Su característica fundamental es el hecho de añadir incertidumbre a la hora de determinar la activación o no de la correspondiente neurona (semejanza con una neurona biológica). Esta incertidumbre otorga mayor flexibilidad a las RNA.

\section{RESULTADOS EXPERIMENTALES}

Hasta ahora se ha descrito cómo para la construcción de una RNA es necesario diseñarla estableciendo variantes de entrada-salida y su topología. A continuación es necesario llevar a cabo las fases de aprendizaje o entrenamiento y la de validación o prueba. En la de entrenamiento se le proporciona a la red un conjunto de casos resueltos para que la red ajuste sus parámetros. En la validación se introducen datos de entrada de otro conjunto distinto de datos resueltos y se comprueba que la red resuelve dichos casos de forma adecuada. Si existen errores en el entrenamiento o en la validación, se debe volver a reajustar o rediseñar la red.

Las 200 muestras seleccionadas se van a separar en dos partes. Por un lado, el conjunto de entrenamiento (160 muestras) y por otro lado, el conjunto de prueba (40 muestras) (29). En la fase de entrenamiento se asume que se conocen los valores de todas las variables, incluido el coste de construcción. Esto nos permite ajustar los pesos de las neuronas mediante un algoritmo de aprendizaje. El más utilizado es el "algoritmo de corrección hacia atrás", que es una generalización de la regla Delta (14). Dicho algoritmo de aprendizaje consiste en ajustar de forma iterativa los pesos de la red. En concreto, como se conoce la salida (coste de producción) y la entrada (valores de las variables), se ajustan los pesos (iterativamente) para que dada una entrada, se produzca la salida deseada. En la primera iteración los pesos de las neuronas se inicializan aleatoriamente, de tal forma que el error suele ser alto. En las siguientes iteraciones, el algoritmo de aprendizaje modifica los pesos para minimizar en la medida de lo posible dicho error (no necesariamente a cero).

La implementación de la red se ha llevado a cabo mediante el software informático MATLAB (30). Todos los datos se han normalizado entre o y 1 para homogeneizarlos y evitar grandes dispersiones (31). El entrenamiento se ha configurado con 300 iteraciones. Además, se ha utilizado la técnica del ten-fold cross validation (validación cruzada de 10 cruces) para obtener resultados más robustos (32).

La Figura 3 muestra el proceso de entrenamiento.

La Figura 4 (en escala logarítmica) muestra cómo en el proceso de entrenamiento se reduce el error cuadrático medio a lo largo de las 300 iteraciones. En concreto, se observa cómo el error se reduce desde el o,5 hasta 0,01 .

Una vez entrenada la RNA, se puede representar gráficamente el error cometido en cada una de las 160 muestras de test. En la Figura 5 se ilustra para cada muestra (numeradas del 1 al 160 y representadas en el eje abscisas) la diferencia entre el coste real y el coste estimado por la red.

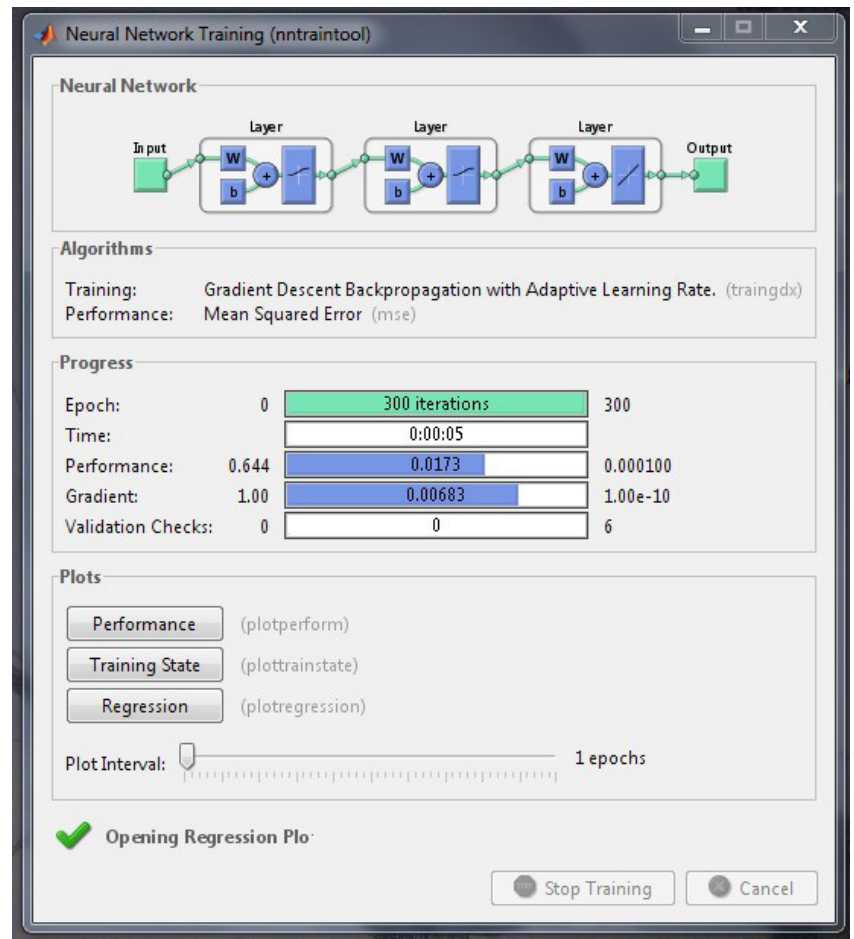

Fig. 3. Pantalla de trabajo de MatLab para RNA Inicial.

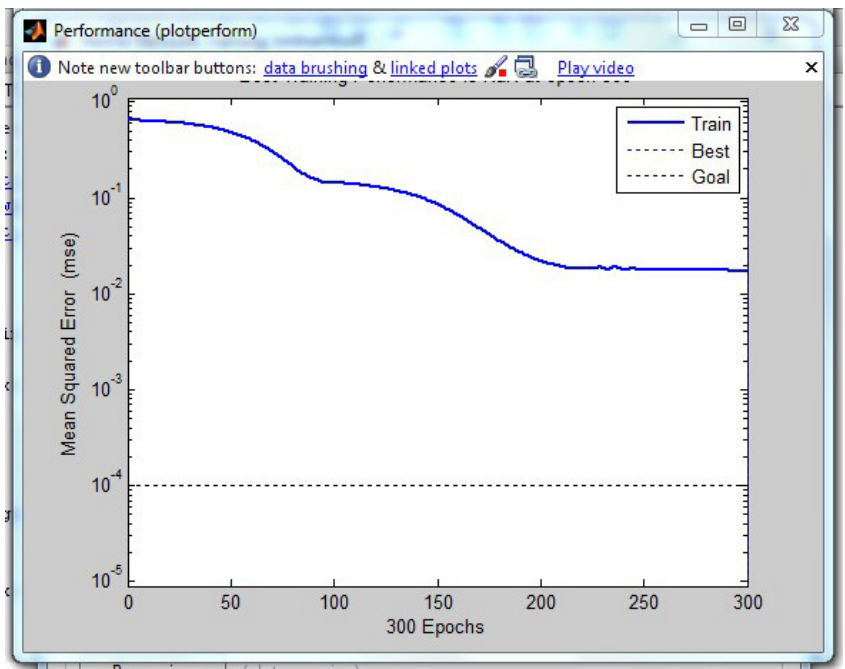

Fig. 4. Evolución del error en las 300 iteraciones.

La mayoría de los datos, se encuentran bajo la línea horizontal de los valores estimados por la red neuronal por debajo del $15 \%$ de error con respecto al valor real. Se trata de un error aceptable y por tanto la RNA funciona satisfactoriamente, incluso sin haber sido comprobada aún en la siguiente fase.

Una vez entrenada la RNA, debemos comprobar su rendimiento con el conjunto reservado para la validación o prueba. Este experimento nos permite comprobar la capacidad de generalización de la red. En este caso, como era de esperar, los errores son mayores, pero salvo para algunos casos puntuales los errores están muy por debajo del $20 \%$ como se observa en la Figura 6.

Para conseguir el segundo objetivo de esta investigación, la segunda parte del experimento persigue conocer qué concep- 


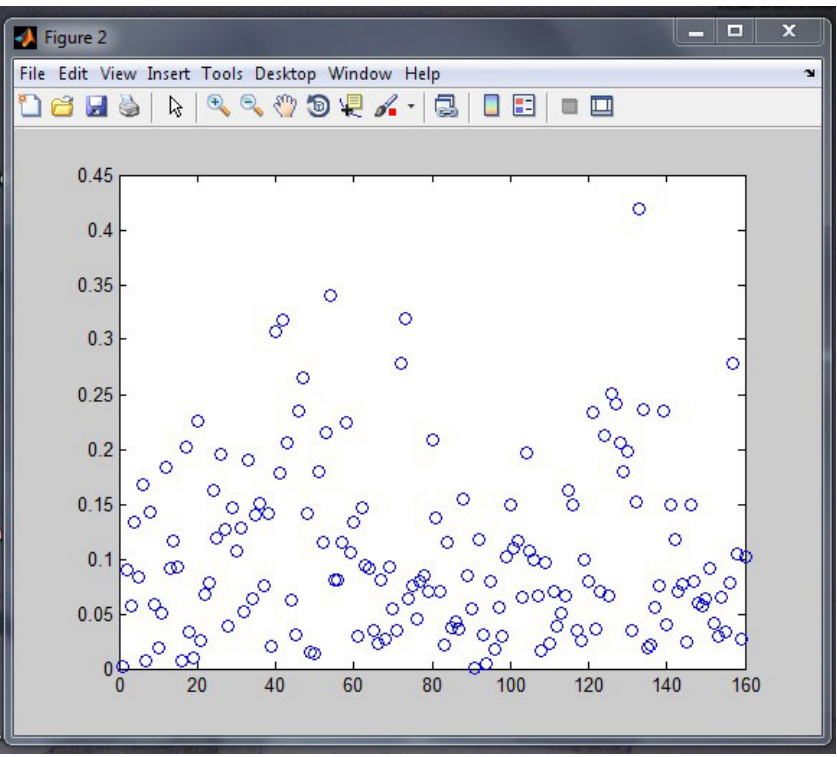

Fig. 5. Dispersión del error en entrenamiento.

tos de entre las variables o circunstancias estudiadas resultan más relevantes a la hora de estimar el coste de la vivienda rústica.

En relación con la jerarquía o relevancia de las variables, es fácil deducir que los pesos adjudicados a cada neurona pueden ser precisamente indicadores ideales para resolver esta cuestión. El problema es cómo considerar las dos capas ocultas de 10 neuronas cada una. Esta "caja negra", formada por dos capas ocultas, enturbia mucho la visión de los pesos individuales, ya que están interrelacionadas y no expresa con nitidez el peso al estar compuesto por la sucesión de dos circuitos intermedios.

Para poder determinar mejor los pesos, se decide probar con una nueva RNA en la cual sólo hay un capa oculta, de modo que se pueda observar directamente los pesos de cada neurona, al sumar las entradas y salidas de ellas directamente. La figura 7 representa la arquitectura de esta nueva RNA.

Para esta situación, al igual que en la anterior, hay que realizar una fase inicial de aprendizaje (16o casos) y otra de comprobación (40 casos). Una vez determinado el nuevo

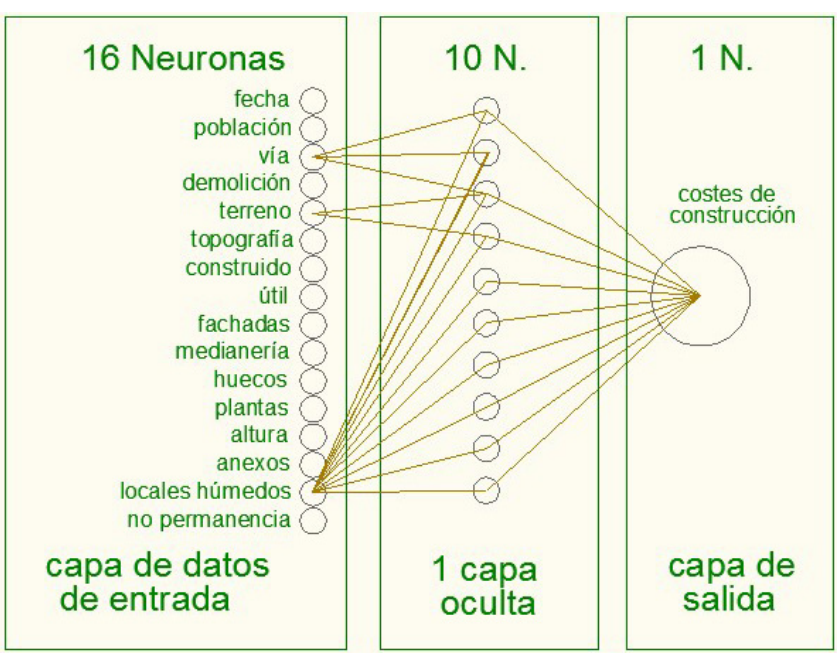

Fig. 7. Esquema de RNA de una capa oculta.

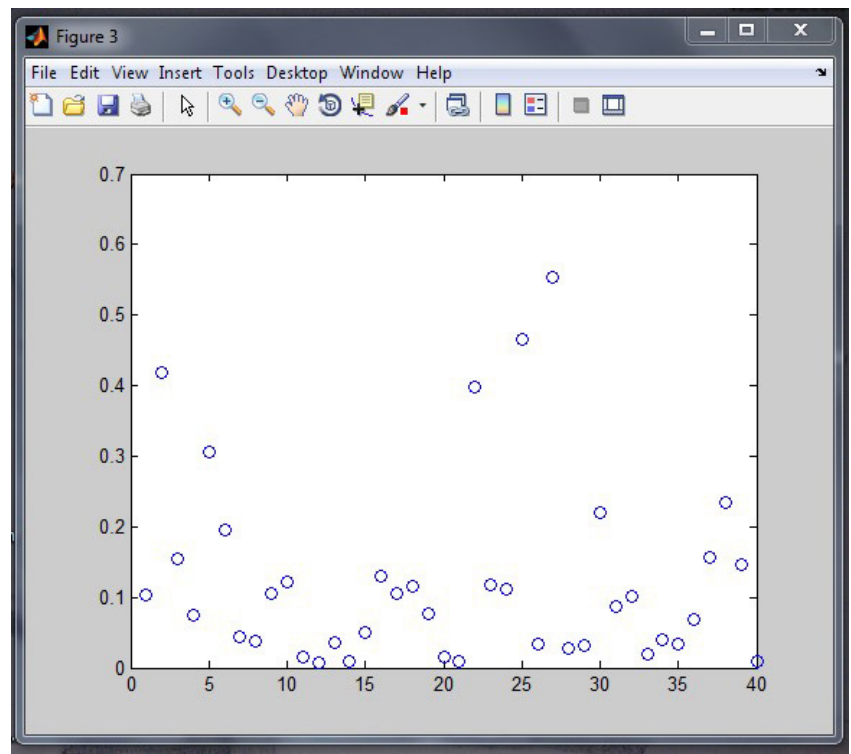

Fig. 6. Dispersión del error en comprobación.

sistema de RNA para la estimación de costes de construcción con una sola capa oculta, se reitera el procedimiento anterior para la RNA inicial y, tras comprobar que presenta un error en torno al $15 \%$ en casi todos los casos, se establecen los pesos de las diferentes neuronas ya que, como sólo se tiene una capa oculta, es directa la lectura de entradas y salidas en la caja negra.

La Figura 8 muestra en una tabla los valores para cada una de las neuronas de la caja negra o capa oculta. El sumatorio de cada uno de estos valores es el peso o relevancia de cada neurona respecto de las otras.

De la tabla de la Figura 8 se observa que las variables de mayor peso se corresponden con las $\mathrm{X}_{15}, \mathrm{X}_{1} \mathrm{y} \mathrm{X}_{7}$ (las variables de locales húmedos, año y superficie construida respectivamente) y el menor peso es para la $\mathrm{X}_{16}$ (superficie de no permanencia). Este resultado de relevancia de las variables es de un orden casi intuitivo; si se tiene en cuenta su interpretación y que el número de veces que se necesita esta neurona para poder calcular el coste es independientemente de su signo. Con este criterio se puede elaborar la Tabla 1 con el orden de relevancia de cada una de las variables, hecho importante a tener en cuenta a la hora de estimar el coste de construcción de la vivienda rústica.

Por tanto, mediante la aplicación de la Inteligencia Artificial, se ha podido establecer un orden de relevancia de las variables que intervienen en el coste de construcción respecto de la incidencia de ellas en dicho coste estimado.

\section{CONCLUSIONES Y DISCUSIÓN}

Esta investigación presenta el uso de RNA para obtener una herramienta de estimación de costes de construcción de viviendas rústicas y por otro lado evaluar los factores que determinan su precio.

El uso de RNA presenta las siguientes ventajas:

- Es sencilla ya que la toma de datos es fácil.

- Es ágil ya que la estimación es rápida. 


\begin{tabular}{|c|c|c|c|c|c|c|c|c|c|c|c|c|c|c|c|}
\hline $\mathbf{x} 1$ & $x 2$ & x3 & $x 4$ & $\times 5$ & x6 & $x 7$ & $x 8$ & $\times 9$ & x10 & x11 & x12 & x13 & x14 & x15 & x16 \\
\hline 0,91 & 2,46 & 0,76 & 0,72 & 3,17 & 1,07 & 1,3 & 0,29 & 0,21 & 2,41 & 1,05 & 2,1 & 2,87 & 0,34 & 1,04 & 0,2 \\
\hline 1,41 & 1,43 & 0,17 & 1,92 & 1,4 & 2,74 & 2,06 & 0,45 & 2,08 & 1,27 & 2,67 & 0,9 & 1,41 & 1,32 & 1,58 & 0,18 \\
\hline 2,21 & 0,64 & 1,34 & 1,49 & 2,36 & 1,77 & 1,06 & 0,27 & 1,08 & 2,79 & 1,99 & 1,11 & 1,24 & 0,15 & 0,87 & 2,47 \\
\hline 2,56 & 2,54 & 1,06 & 2,49 & 1,16 & 0,94 & 1,49 & 1,43 & 0,57 & 0,4 & 1,11 & 45 & 2,02 & 2,62 & 1,44 & 0,08 \\
\hline 1,51 & 0,49 & 0,91 & 0,21 & 0,39 & 1,38 & 15 & 1,16 & 2,02 & 1,2 & 73 & 24 & 88 & 84 & 83 & 7 \\
\hline 0,85 & 1,02 & 2,34 & 0,95 & 0,15 & 0,94 & 2,69 & 1,55 & 1,3 & 0,25 & 2,08 & 1,82 & 79 & 5 & 8 & 3 \\
\hline 0,55 & 2,23 & 2,84 & 2,6 & 0,28 & 1,29 & 0,67 & 0,19 & 1,69 & 0,49 & 0,11 & 1,61 & 0,14 & 2,57 & 2,03 & 1,59 \\
\hline 2,14 & 1,75 & 0,98 & 0,6 & 2,05 & 2,35 & 0,62 & 2,53 & 2,27 & 0,79 & 0,27 & 0,62 & 0,76 & 2,38 & 1,97 & 0,11 \\
\hline 3,04 & 0,58 & 0,23 & 2,09 & 0,14 & 1,84 & 3,12 & 2,43 & 1,73 & 1,11 & 0,31 & 0,62 & 0,34 & 0,72 & 1,47 & 1,14 \\
\hline 2,11 & 2,26 & 0,86 & 0,43 & 2,47 & 1,53 & 2,77 & 1,23 & 1,48 & 1 & 0,9 & 0,23 & 0,82 & 0,29 & 2,26 & 1,95 \\
\hline 17,3 & 15,4 & 11,7 & 13,5 & 13,6 & 15,8 & 16,9 & 11,5 & 14,4 & 11,7 & 12,8 & 11,7 & 13,3 & 14,4 & 18,1 & 9,35 \\
\hline
\end{tabular}

Fig. 8. Cuadro de Pesos de las 16 neuronas de la RNA de una capa oculta.

Tabla 1. Orden de relevancia de las variables.

\begin{tabular}{|l|c|}
\hline \multicolumn{1}{|c|}{ Jerarquía } & Peso neuronal \\
\hline $\mathrm{x}_{15}:$ superficie de locales húmedos & 18,10 \\
\hline $\mathrm{x}_{1}:$ año de ejecución & 17,30 \\
\hline $\mathrm{x}_{7}:$ superficie construida & 16,80 \\
\hline $\mathrm{x}_{6}:$ topografía del solar & 15,80 \\
\hline $\mathrm{x}_{2}:$ población o localidad & 15,40 \\
\hline $\mathrm{x}_{9}:$ superficie de fachada & 14,40 \\
\hline $\mathrm{x}_{14}:$ anexos & 14,40 \\
\hline $\mathrm{x}_{5}:$ tipo de terreno & 13,60 \\
\hline $\mathrm{x}_{4}:$ demolición previa & 13,50 \\
\hline $\mathrm{x}_{13}:$ altura de coronación & 13,30 \\
\hline $\mathrm{x}_{11}:$ superficie de huecos & 12,80 \\
\hline $\mathrm{x}_{3}:$ ancho de vía a la obra & 11,70 \\
\hline $\mathrm{x}_{10}:$ superficie de medianera & 11,70 \\
\hline $\mathrm{x}_{12}:$ número de plantas & 11,70 \\
\hline $\mathrm{x}_{8}:$ superficie útil & 11,50 \\
\hline $\mathrm{x}_{16}:$ superficie de no permanencia & 9,35 \\
\hline
\end{tabular}

- Es fiable ya que se tiene un nivel de confianza alto.

- Es una herramienta útil para la Administración Pública, los promotores, los técnicos y entidades financieras.

Esta herramienta de estimación frente algunos modelos actuales presenta las siguientes ventajas:

- No requiere gran definición del edificio.

- Permite cambios en decisiones iniciales.

- No utiliza variables técnicas.

- Considera las variables del lugar.

- Establece un nivel de certeza adecuado.

Los errores cometidos por la estimación de la red neuronal son del $15 \%$ para la vivienda rústica de la ciudad de Cáceres (200 casos entre 2001-2008). Ceular, Caridad y Ocerin (12), utilizan 710 viviendas elevando el error hasta el 17,30\%, con datos de 1998 en Córdoba. Núñez Tabales et al. aumentan el número de casos a 2.888 y consiguen para la misma ciudad, errores del 13,69\% con datos de 2006 (18) y en Sevilla con 698 casos, un error del 16,51\% con datos de 2013 (19). Parece que aumentar el número de casos con el que se programa la red neuronal reduce el error aunque no significativamente. Por otro lado no se aprecia variación del error por el hecho de trabajar en distintos espacios temporales.

Los errores en el estudio del precio rústico en Cáceres son más bajos por la poca variabilidad de los datos (en este caso los precios), y de la poca heterogeneidad de otras variables causales que son más difíciles de medir con precisión.

En cuanto a las variables que mayor influencia tienen sobre el precio final del inmueble, la investigación coloca en primer lugar la superficie de lugares húmedos (baños y cocina) seguido de la superficie construida y la antigüedad. Para viviendas urbanas en grandes y medianas ciudades el factor más influyente es la superficie total construida seguida de la ubicación y en tercer lugar la antigüedad (18),(19). Para locales comerciales también prevalece la superficie sobre el resto de variables, destacando en segundo lugar el índice de conservación y en tercer lugar la ubicación (33).

El modelo planteado resulta correcto por dos razones fundamentales:

a) Se parte de una tipología adecuada ya que existen variaciones en diseño y coste pero guardan ciertas similitudes que evitan una dispersión excesiva de los datos.

b) El ámbito territorial es una unidad geográfica apropiada desde el punto de vista socioeconómico y cultural.

Si hay algo que aporta esta investigación, por encima incluso del método de estimación ya obtenido, es el hecho de acercarse a los problemas de la arquitectura desde un nuevo enfoque, estudiar variables interrelacionadas desde el punto de vista de la lógica, a través de las Redes Neuronales Artificiales.

\section{AGRADECIMIENTOS}

A la Junta de Extremadura y al Colegio Oficial de Arquitectos de Cáceres por toda la información suministrada para realizar esta investigación. 


\section{REFERENCIAS}

(1) Polion, MV. (1992). Los diez libros de arquitectura. Ediciones Akal. ISBN: 978-84-460-0150-8.

(2) Bode, J. (2000). Neural networks for cost estimation: simulations and pilot application. International Journal of Production Research 38(6): 1231-1254.

(3) Pina Ruiz, P. (1992). Banco de costos en Obras de Arquitectura y Urbanismo 1991/1992. Colegio Oficial de Arquitectos de Murcia.

(4) Carvajal Salinas, E. (1992). El predimensionado de coste en Arquitectura. Modelos P2CT y P2CR. Consejería de Obras Públicas y Transportes, Dirección General de Arquitectura y Vivienda, Junta de Andalucía.

(5) Ingenieros, S.C. (2002). Manual del Usuario Arquímedes y Control de Obra. Versión 2002. Ed. Cype Ingenieros, SA Alicante. Disponible online: http://manual.arquimedes.cype.es/\#Visualizacion_descarga_manual_arquimedes.

(6) Pfleeger, SL., Wu, F., Lewis, R. (2005). Software cost estimation and sizing methods: issues, and guidelines. Vol 269. Rand Corporation. California, USA. ISBN 0-8330-3713-7.

(7) Rey Carmona, FJ. , Nuñez Tabales, JM. (2017). Alternativas para la valoración de inmuebles urbanos. Revista Publicando, 4 (11) : 3-19. Disponible en http://rmlconsultores.com/revista/index.php/crv/article/view/290. Acceso 23 de noviembre de 2017.

(8) Peterson, S., Flanagan, A. (2009). Neural network hedonic pricing models in mass real estate appraisal. Journal of Real Estate Research, 31(2):147-164. Disponible en https://search.proquest.com/docview/200319261/fulltextPDF/2BFDCF 815DB143DCPQ/1?accountid=17204. Acceso 23 de noviembre de 2017.

(9) Caridad y Ocerin, JM., Nuñez Tabales, JM., Ceular Villamandos, N. (2008). Metodología de precios hedónicos vs. Redes Neuronales Artificiales como alternativas a la valoración de inmuebles. Un caso real. CT. Catastro: revista del Centro de Gestión Catastral y Cooperación Tributaria. Disponible en http://www.catastro.minhap.es/documentos/publicaciones/ct/ct62/ct62_3.pdf. Acceso 23 de noviembre de 2017.

(10) Chiarazzo, V., Caggiani, L., Marinelli, M., Ottomanelli, M. (2014). A Neural Network based model for real estate price estimation considering environmental quality of property location. Transportation Research Procedia, 3: 810-817.

(11) Fachrurrazi, Husin, S., Tripolo, Mubarak. (2017). Neural Network for the Standard Unit Price of the Building Area. Procedia Engineering, 171: 282-293.

(12) Ceular, N., Caridad y Ocerín, JM. (2001). Un análisis del mercado de la vivienda a través de redes neuronales artificiales. Estudios de Economía Aplicada, 18(2): 67-81.

(13) Mohamed Amar, R. (2002). Estimación del precio de la vivienda urbana mediante redes neuronales artificiales: Estudio de un caso. XII, Jornadas Hispano-Lusas. Covilhà, Portugal.

(14) Gallego Mora-Esperanza, J. (2004). La inteligencia artificial aplicada a la valoración de inmuebles. Un ejemplo para valorar Madrid. CT. Catastro: revista del Centro de Gestión Catastral y Cooperación Tributaria, 50: 51-67.

(15) García Rubio, N. (2004). Diseño de redes neuronales artificiales para el mercado inmobiliario. Aplicación a la ciudad de Albacete. Tesis Doctoral. Universidad de Castilla-La Mancha.

(16) Lara Cabeza, JM., et al. (2005). Aplicación de las Redes Neuronales Artificilaes el Campo de la Valoración Inmobiliaria. Mapping: Map and Sigconsulting, 104: 64-69.

(17) Landajo, M., Bilbao, C.; Bilbao, A. (2012). Nonparametric neural network modeling of hedonic prices in the housing market. Empirical Economics, 42(3) : 987-1009, doi: http://dx.doi.org/10.1007/soo181-011-0485-9

(18) Nuñez Tabales, JM., Caridad y Ocerin, JM., Ceular Villamandos, N. et al. (2012). Obtención de Precios Implícitos para Atributos Determinantes en la Valoración de una Vivienda. Revista Internacional de Administración y Finanzas, 5(3): 41-54. Disponible en https://papers.ssrn.com/sol3/papers.cfm?abstract_id=1954027. Acceso 23 de noviembre de 2017.

(19) Nuñez Tabales, JM., Rey Carmona, FJ., Caridad y Ocerin, JM. (2016). Artificial Intelligence (AI) techniques to analyze the determinants attributes in housing prices. Inteligencia Artificial, 19(58): 23-38. Disponible en http://journal.iberamia.org/index.php/intartif/article/view/37. Acceso 23 de noviembre de 2017.

(20) Alcazar Molina, MG., Ariza Lopez, FJ.(2004). Situación actual de la valoración catastral rústica en España: propuesta de un modelo alternativo. CT. Catastro: revista del Centro de Gestión Catastral y Cooperación Tributaria. Disponible en: http://www.catastro.minhap.gob.es/documentos/publicaciones/ct/ct52/o4_catastro.pdf. Acceso 23 de noviembre de 2017

(21) Azcona, JP. (2014). Modelo Fuzzy de determinación del valor unitario de edificación destinada a vivienda con fines catastrales. CT. Catastro: revista del Centro de Gestión Catastral y Cooperación Tributaria. Disponible en: http://www. catastro.minhap.gob.es/documentos/publicaciones/ct/ct82/1.pdf. Acceso 23 de noviembre de 2017.

(22) Ayuntamiento de Cáceres. (2014). Plan de infraestructuras para la movilidad urbana sostenible. Disponible en: http:// www.zetaestaticos.com/comun/upload/o/580/580017.pdf. Acceso 21 de mayo de 2018

(23) Gobierno de España. (2002). Ley 6/ 2002, de 27 de junio, de medidas de apoyo en materia de autopromoción de vivienda, accesibilidad y suelo. Boletín Oficial del Estado de 22 de agosto de 2002, núm. 221. Disponible en https://www.boe. es/buscar/pdf/2002/BOE-A-2002-16785-consolidado.pdf. Acceso 23 de noviembre de 2017

(24) Nuñez Tabales, J., Caridad, JM., Villamondos, NC et al. (2009). Estimación del precio de la vivienda mediante redes neuronales artificiales (RNA) en diferentes marcos temporales. Metodología de Encuestas 11(1): 79-101. Disponible en http://casus.usal.es/pkp/index.php/MdE/article/download/994/935. Acceso 23 de noviembre de 2017

(25) Junta de Extremadura. (2009). Decreto 113/2009, de 21 de mayo, por el que se regulan las exigencias básicas que deben reunir las viviendas en el ámbito de la Comunidad Autónoma de Extremadura, así como el procedimiento para la concesión y control de la cédula de habitabilidad.

(26) Calvo Gomez, F. (1994). Teoría del error muestral. Estadística aplicada. $2^{\text {a }}$ Edición, Deusto. Barcelona. ISBN:978-84234-0400-1 
(27) Skapura, D. M. (1996). Building neural networks. Addison-Wesley Professional. New York. USA. ISBN 0-201-53921-7

(28) Florez, R., Fernandez, JM. (2008). Las redes neuronales artificiales. Fundamentos teóricos y aplicaciones prácticas. Serie metodología y análisis de datos en ciencias sociales. Editorial Netbiblo. ISBN: 978-84-9745-246-5.

(29) Zuna, HT., Hadiwardoyo, SP., Rahadian, H. (2016). Developing a model of toll road service quality using an artificial neural network approach. International Journal of Technology, 7(4): 562-570. doi: http://dx.doi.org/10.14716/ijtech. v7i4.2612

(30) Carbonel, JM., Defreitas, D. (2010). Aplicación de diferentes arquitecturas de RNA sobre datos de paquetes de red en Matlab con y sin reducción de características, doi: http://dx.doi.org/10.13140/2.1.3964.2887.

(31) Nuñez Tabales, J., Rey Carmona, F., Caridad y Ocerin, JM. (2013). Implicitprices in urban real estate valuation. Revista de la Construcción, 12(2). Disponible en http://www.redalyc.org/html/1276/127629284009/. Acceso 23 de noviembre de 2017.

(32) Van Der Gaag, M., Hoffman, T., Remijsen, M. et al. (2006). The five-factor model of the Positive and Negative Syndrome Scale II: a ten-fold cross-validation of a revised model. Schizophrenia research, 85(1): 280-287. DOI: https://doi. org/10.1016/j.schres.2006.03.021.

(33) Nuñez Tabales, JM., Rey Carmona, FJ. and Caridad JM. (2017). Redes neuronales (RN) aplicadas a la valoración de locales comerciales. Informes de la Construcción, 69 (545): 179, doi: http://dx.doi.org/10.3989/ic.15.053.

\section{MATERIAL ADICIONAL}

AÑO 199619971998199920002001200220032004200520062007 total

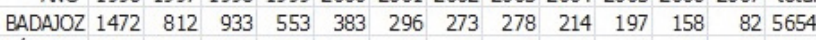

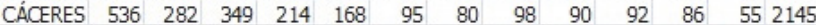

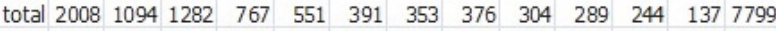
$\begin{array}{llllllllllllllll}\% & 25,7 & 14 & 16,4 & 9,83 & 7,07 & 5,01 & 4,53 & 4,82 & 3,9 & 3,71 & 3,13 & 1,76 & 100\end{array}$

Fig. A. Actuaciones en la Comunidad de Extremadura.

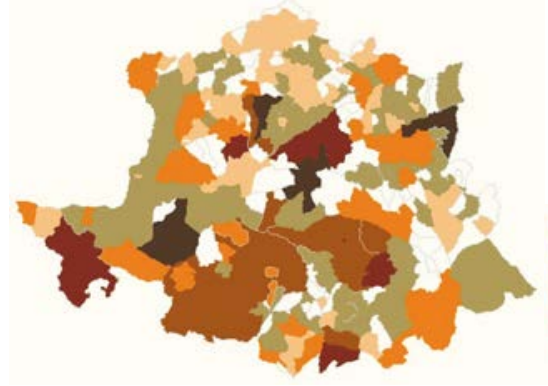

Fig. B. Distribución de intervenciones del año 2001 al 2008 en la provincia de Cáceres.

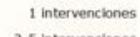
1-15 intervenciones 16-20 intervenciones more 20 intervenciones

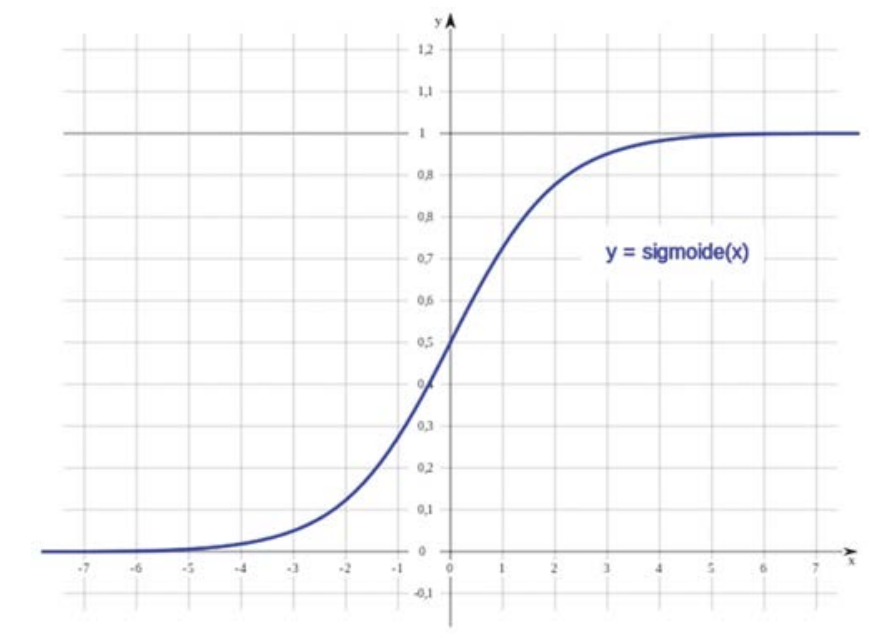

Fig. D. Curva matemática de función sigmóide.

$* * *$

(2)
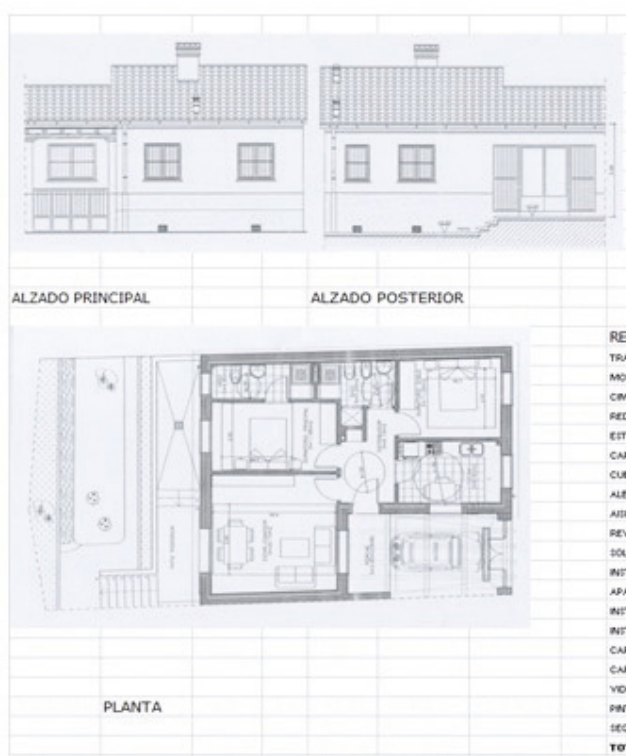